\title{
Examination of Best Practices for Waterfront Regeneration
}

\author{
Dora Papatheochari, Department of Planning and Regional Development, University of Thessaly,
} thpapath@uth.gr

\begin{abstract}
A lot of cities in the past few decades have used waterfront recreation policies as a solution for the revitalisation of abandoned and degraded urban areas. Moreover, the role of the waterfront has been enhanced by its position as an important node for the land and sea and an entrance through which the city develops relationships with other areas. The waterfront regeneration is connected to social, economic and environmental benefits when based on integrated management and planning. Examples of the past have resulted in the enhancement of the sense of community and quality of life and the attraction of economic resources. The interest for the regeneration of the urban waterfront began in 1963 with the recreation of Baltimore's Inner Harbour, a project that transformed the degraded harbor zone to an urban leisure centre altering the economic and spatial dynamics of the area. Since then a number of successful and unsuccessful recreation projects has taken place in many cities. The increasing importance for quality of urban life and the emerging pollution problems in the urban coast have created a demand for public space that would replace the 'heavy' activities of the urban coastal zone. Although waterfronts are expected to act as opportunities for the revitalization of a coastal city, it is difficult to achieve a balance between the existing functions. This paper aims at exploring the basic strategies that have led to successful examples of waterfront recreation and at assessing the challenges and issues that coastal cities have to face.
\end{abstract}

Key words: waterfront, regeneration, coastal zone, integration

\section{Introduction}

The way that the urban waterfront is being perceived has changed through the years. In the past, it used to incorporate 'heavy' activities -more often- linked to the previous development of port uses while today there has been a tendency to small scaled, sustainable functions and public space. The new trends in human behavior and technology have also changed leisure activities and contributed to the increase of the importance of urban image. According to Jones (1998) the focus on waterfront regeneration has emerged through the increase of leisure time, the need to preserve the city's historical heritage and the growing importance of the environmental and social aspects of the urban coast.

The role of the urban waterfront changes according to its purpose and its relationship to the city. The urban waterfront could either act as the city's frontier that distinguishes the city from the sea or the means to connect them.

On the one hand, the waterfront's role is usually being enhanced by its proximity to the historical city centre and the advantages of direct access and connections to the rest of the city. Moreover, the connection of the waterfront to historical buildings and neighbourhoods offers great opportunities for its regeneration. On the other hand, water constitutes an important attraction for the city offering the direct contact to the sea. Therefore, its role is substantial for the city's interrelationships (Millspaugh, 2001). Therefore, the waterfront could

This is an Open Access article distributed under the terms of the Creative Commons Attribution-Noncommercial License 3.0, which permits unrestricted use, distribution, and reproduction in any noncommercial medium, provided the original work is properly cited. 
act as an important node for the exchange of goods and people while expressing the city's culture and image, attracting people and investment and enhancing local economy.

Although each coastal city displays different characteristics regarding its waterfront, it seems that there are some common elements such as its uniqueness and its perception as a frontier and a standard mark point for the city.

A few of the most important issues in waterfront regeneration is the spatial competitiveness between the marine and urban uses (Cook et al, 2001), the port and city interfaces and the changing socioeconomic conditions in coastal cities.

\section{Experience of waterfront regeneration}

The first examples of waterfront regeneration came in the 70's from cities in the United States. The USA experience gave the first successful stories and mistakes on waterfront regeneration that was used later on by other countries as a guide for their projects. The model used by most American port cities involved a mixture of uses (residential, commercial, retail, recreational, service and tourist activities). This model was widely accepted by other countries that also applied it in their projects. The most influential examples of the US waterfront regeneration projects are considered to be Baltimore's Inner Harbour, Boston's Quincy Market, New York's Pierhead Building, San Diego's waterfront village and San Francisco's Giradelli Square and Pier 63 (Jones, 1998). Baltimore's Inner Harbour regeneration influenced many projects in Europe (from Scandinavia, UK and the Netherlands to Spain and all southern Europe) and worldwide (Australia, Japan, Latin America, the Middle East and South Africa).

Fig. 1. Baltimore's Inner Harbour

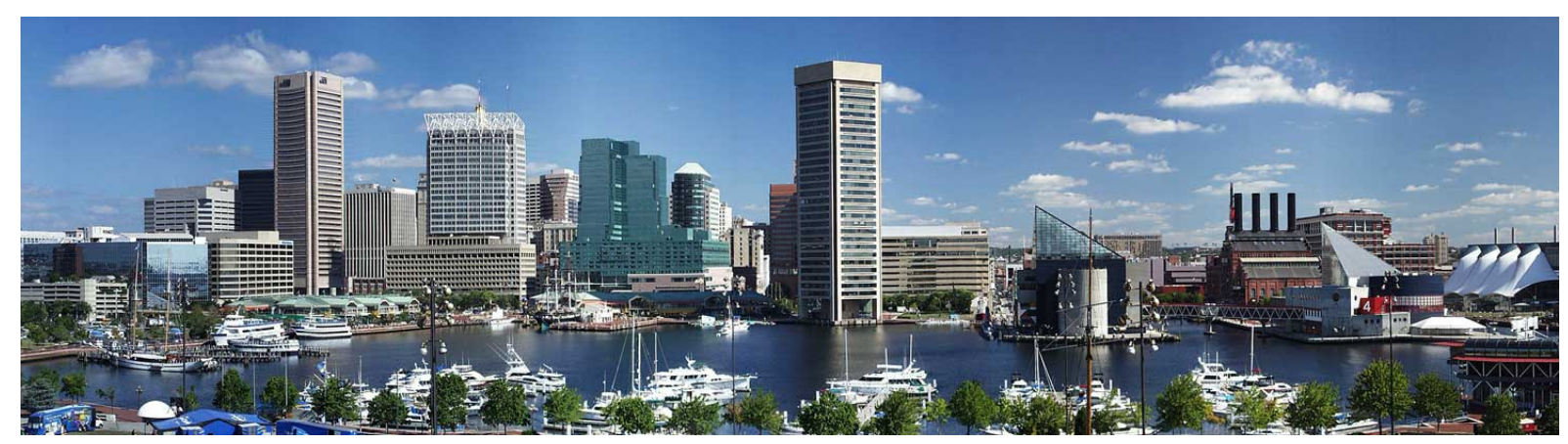

The focus in the UK port cities was the redevelopment of old industrial declined areas and the London Docklands transformation has been a guide of 'dos' and 'don'ts' for later regeneration projects in Europe. The city of Barcelona has played an important role in waterfront regeneration practices which started with the hosting of the Olympic Games of 1992 and continued with further developments and the organisation of other activities. 
Fig. 2. London Docklands

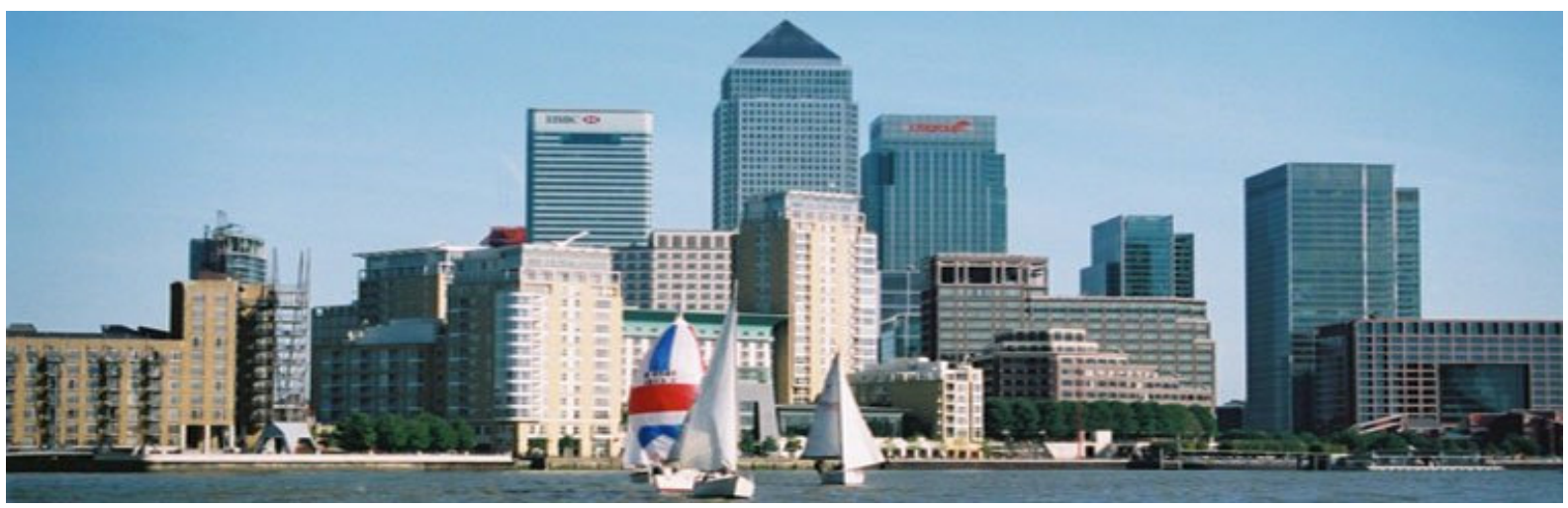

Vancouver is perceived as a successful example of an integrated approach for the waterfront regeneration facing the urban waterfront as an important extension of the city and not a separate part of it, linking it directly to the historical city centre. This linkage has been achieved through the creation of a tight pattern of interventions and activities. The basic achievements of the Vancouver's Central Area Plan was the enhancement of city life, the car use reduction and the enhancement of the sense of community through the reduction of time travel for basic amenities, the alternative means of public transportation, the reduction of energy consumption and the protection of the coastal and water ecosystems (Marshall, 2001).

\section{Fig. 3. Vancouver waterfront}

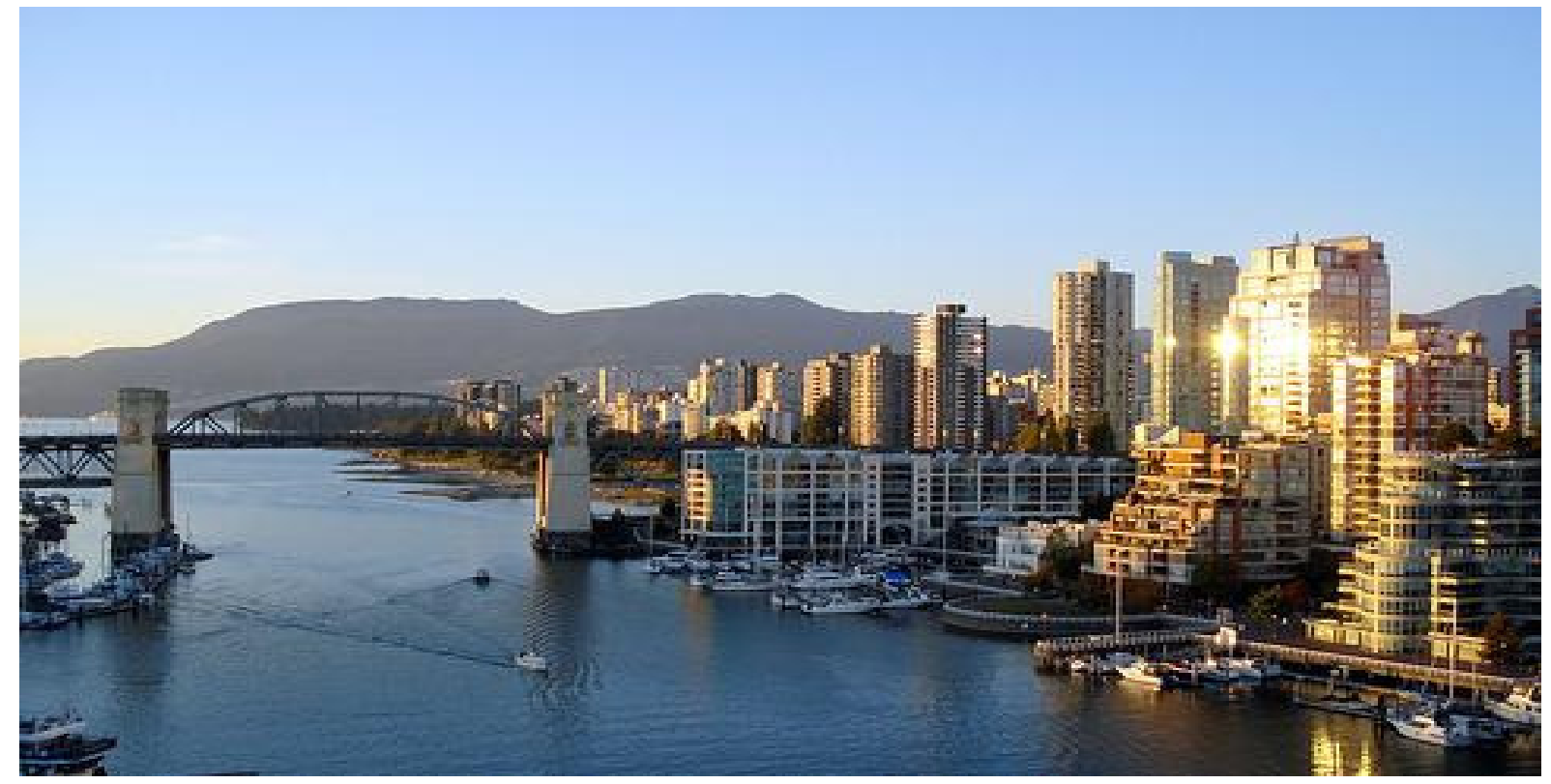

The implementation of the existing policies for waterfront regeneration does not necessarily lead to successful results. Each city and its waterfront should be perceived differently 
according to their own character and position. Those policies though could act as reference point for alternative approaches and planning measures.

\section{Benefits and problems of waterfront regeneration}

The existing literature views waterfront regeneration as an opportunity for coastal cities to enhance their economy and promotion. Some of the most distinctive advantages of waterfront regeneration are:

- The increase in property values (when enhancing local economy)

- The increase in economic investment on degraded areas

- The attraction of visitors and resources

- The improvement of the environmental conditions through the use of sustainability methods that protect the coastal ecosystems

- The preservation of historical heritage

- The improvement of water quality through the advanced management processes

- The improvement of the city's image which leads to better marketing strategies

- The provision of better services of transport, social services etc. (Jones, 1998).

Although, in theory these benefits should be met in every regeneration project, very often the actions taken do not agree with the original plan. This leads to short term benefits and sporadic interventions which cause future conflicts. Some of these conflicts are:

- Reduction in waterfront project funding

- Loss of the waterfront's cultural identity through the implementation of actions that imitate other cities' measures and do not meet with the city's needs, interests and special characteristics

- Conflicts of interest between private and public sector

- Conflicts associated with working areas and residential neighborhoods

- Commercial failures or exploitation at the public community's expense

- Land use conflicts

- Controversy of social benefits (social accessibility and public facilities) (Jones, 1998).

- Delays in decision making processes and implementation that could lead to adjustment problems to economic, political and social changes

- Environmental pressures (human activities versus coastal ecosystems)

\section{Lessons learned}

According to the international experience, the usual goals of waterfront regeneration projects are the redefinition of waterfront's role in the urban context, the improvement of urban image and the transformation of the economy (Butuner, 2006). More specifically, the usual aims are:

- The reuse of abandoned buildings and areas 
- The regeneration of degraded neighborhoods

- The creation of spaces open to the wider public

- The achievement of high accessibility

- The reduction of the use of private cars and the supply of alternative means of transportation

- The development of waterborne transport

- The focus on the environmental and urban elements of the waterfront

- The protection of water quality

- The securing the growth and capital investment (Wakefield, 2007).

One of the most important aspects of waterfront regeneration is the identification of the relationship between the city and the specified waterfront area. Although a planner could set limits to the waterfront area, the complexities of a city usually develop beyond those lines and recognizing those interrelations could prove vital for a project's success (Goodwin, 2000). Moreover, waterfront planning and management should take into account the possible external changes and pressures that may occur and affect coastal cities and their waterfronts in order to achieve long term results (Abaya Gomez, 2008).

There also seems to be essential for the waterfront regeneration the incorporation of economic and social aspects in the context of the environmental policy and the connection of the waterfront with the social, economic and physical activity of the rest of the city, incorporating -in this way- all the factors that could affect its development.

The most common uses met at the urban waterfront are commerce, leisure, residence and office. The incorporation of these uses in a waterfront regeneration plan does not necessarily ensure success. The decision of the uses suitable for each case and the connections between them should be a result of an integrated strategy taking into account the goals, needs and characteristics of the waterfront itself and the city as a whole. Sporadic actions usually lead to short-term solutions that would probably create larger problems in the future. Although waterfront regeneration projects promote land use mixture and variation of activities, there should be a distinct definition of those though these planning strategies.

According to Bruttomesso (2001), the best conditions to avoid the aforementioned problems and conflicts in waterfront regeneration are the preservation of the waterfront identity with activities that connect the 'old' to the 'new' whilst securing the diversity, the combination of uses and their connections, the creation of tight networks with the rest of the city's functions, the emphasis in quality (water and coastal quality restoration, openness and accessibility to the public), administrative effectiveness and the acknowledgement of the water as an important resource of the city.

Two of the most distinctive factors that affect each other along with waterfront regeneration processes are the regulatory framework and political will and cooperation (avoidance of political fragmentation). Strategies based on effective regulatory frameworks that do not restrain integrated planning and management procedures and on administrative factors that do not compromise long-term planning efforts, present successful planning and managerial models and provide the city with substantial development results. 
Public participation could act as a substantial factor for the success of waterfront regeneration processes either at an early stage of planning and policy or later in the decision making procedure. Public involvement could lead to social integration and acceptance and avoidance of undesired reactions. There are some successful examples of smaller scale projects than the ones mentioned above which owe a large part of their success to the creation of a public-private partnership. These are Cape Town's waterfront revival, Swansea, Portsmouth and Amsterdam waterfront renewal etc. This cooperation between the public and the private is usually expressed in the activities located at the waterfront, the areas controlled by the public and the private sector and the factors that hold the management of the involved areas and activities.

An overall good development plan describing the phases of the regeneration could help better organizing the project's budget and implementing the planned actions. The incorporation of future changes caused by the regeneration actions planned is essential for a better long term management of the given area. According to Gordon, in the case of Boston Naval Shipyard, plans which did not provide generous public space led to political trouble.

Generally, it is evident that a successful implementation of a regeneration project requires public and private funding, provision of high quality services, administrative effectiveness, promotion of tourism and public participation. Those objectives could be met through the development of the appropriate -for each case- activities, services and infrastructures and the effective mixture of land and sea uses whilst preserving the distinctive identity of the waterfront (Hoyle, 2001: 305).

In any case there is the need for a specific strategy that could be implemented for a specified area and target population of the city's waterfront. The aim is to keep a reference point through the overall process in order to deteriorate unwanted social and spatial consequences. This could also be achieved through the creation of a specific management entity for the implementation of the regeneration project that would be independent from public authorities and private interests and would ensure that the planning goals and initial objectives of the strategy would meet the actual actions of the implementation.

\section{Final remarks}

The lessons learned through the last few decades on waterfront regeneration tend to support development strategies that involve more balanced and manageable actions than impressive and overambitious projects. Concerning land use, private-public sector partnerships are strongly supported for land use integration. Although the news of the results and actions of the various regeneration projects spread quickly, each city has its own character, identity, history and role and should be examined accordingly.

The complexity of the waterfront regeneration demands a good knowledge of international processes combined with an understanding of the local character and environment of a city and its waterfront. The difficulty of bringing those two aspects together is what makes waterfront regeneration so indistinct for the factors that are involved in this procedure (Hoyle, 2001: 297).

International literature has revealed that although applied waterfront regeneration projects could teach a lot, the factors of scale and character of each city play an important role when planning a new project. 


\section{References}

Abaya Gomez, J.E. (2008) 'Waterfront Design without Policy? The Actual Uses of Manila's Baywalk', Cities, 25, 86-106

Bruttomesso, R. (2001) "Complexity on the urban waterfront" in R. Marshall (eds.), Waterfronts in Post-industrial Cities, New York: Spon Press, 39-51

Butuner, B. (2006) 'Waterfront Revitalization as a Challenging Urban Issue', 42nd ISoCaRP Congress

Cook, A. et al (2001) "Port and city relations: San Francisco and Boston" in R. Marshall (eds.), Waterfronts in Post-industrial Cities, New York: Spon Press, 117-133

Goodwin, R.F. (1999) 'Redeveloping Deteriorated Urban Waterfronts: The Effectiveness of U.S. Coastal Management Programs', Coastal Management, 27, 239-269

Gordon, D.L.A. (1999) 'Implementing urban waterfront redevelopment in an historic context: a case study of the The Boston Naval Shipyard', Ocean and Coastal Management, 42 (1011), 909-931

Hoyle, B. (2001) 'Lamu: Waterfront Revitalization in an East-African Port City', Cities, 18 (5), 297-313

Jones, A. (1998) 'Issues in Waterfront Regeneration: More Sobering Thoughts: A UK Perspective', Planning Practice and Research, 13 (4), 433-442

Marshall, R. (2001) "Connection to the waterfront: Vancouver and Sydney" in R. Marshall (eds.), Waterfronts in Post-industrial Cities, New York: Spon Press, 17-38

Millspaugh, M.L. (2001) "Waterfronts as catalysts for city renewal" in R. Marshall (eds.), Waterfronts in Post-industrial Cities, New York: Spon Press, 74-85

Wakefield, S. (2007) 'Great expectations: Waterfront redevelopment and the Hamilton Harbour Waterfront Trail', Cities, 24 (4), 298-310 